\title{
Assessing urban water security and climate change adaptation in Makassar, Indonesia
}

\author{
G. Tjandraatmadja ${ }^{a}$, D.G.C. Kirono ${ }^{b}$, L. Neumann ${ }^{a}$, S. Larson ${ }^{c}$, S. Stone-Jovicich ${ }^{\text {, }}$, R.A. Barkey , $^{\mathrm{e}}$
} A. Amran ${ }^{\mathrm{e}}$, M. Selintung ${ }^{\mathrm{e}}$

${ }^{a}$ CSIRO Land and Water, Highett, Victoria, Australia ${ }^{b}$ CSIRO Marine and Atmospheric Research, Aspendale, Victoria, Australia, ${ }^{c}$ Aqua-energie Pty Ltd, Australia, ${ }^{d}$ CSIRO Ecosystems Science, ${ }^{e}$ University Hasanuddin, Makassar, Indonesia.

Email:grace.tjandra@csiro.au,luis.neumann@csiro.au,dewi.kirono@csiro.au,silva.larson@gmail.com, Samantha.stone-jovicich@csiro.au,rolandbarkey@gmail.com,amhutan@yahoo.com, mary.selintung@yahoo.com

\begin{abstract}
Understanding the potential implications of global and regional climate change is important for decision-makers and planners to make better decisions regarding infrastructure needs and future planning. This is particularly important in cities in developing regions, which often have a history of under-investment in infrastructure and services and experience constraints in finance, resource access, limited data and capacity, whilst experiencing rapid population and economic growth. Makassar city, the capital of South Sulawesi, Indonesia, is a typical example. With a population of 1.3 million people, increasing access to clean water supply to a millennium development goal level is a key government objective. However, access to water depends on multiple factors: the city's surface water supplies which are subject to strong seasonal effects, the availability and condition of the infrastructure for water treatment and distribution, water use patterns and the resources and capacity of the city to invest and maintain their system.
\end{abstract}

To aid in the assessment of water security and to build the capacity in the region, CSIRO and Hasanuddin University in conjunction with local government agencies developed a framework for water security assessment (Figure 1). The framework included climate change projections, evaluated its potential impacts on surface water hydrology and urban water security for Makassar city and then focused on the development of adaptation options. Integral to the development of the framework was the participation of stakeholders (government agencies, researchers, NGOs and academics) at all stages of the process. By integrating topdown and bottom up knowledge (scientific modelling outputs and local knowledge) the project was able to identify vulnerabilities and assess the effectiveness of planned infrastructure to climate change and urban development and to identify a range of adaptation options which can assist in increasing the future security of water supply.

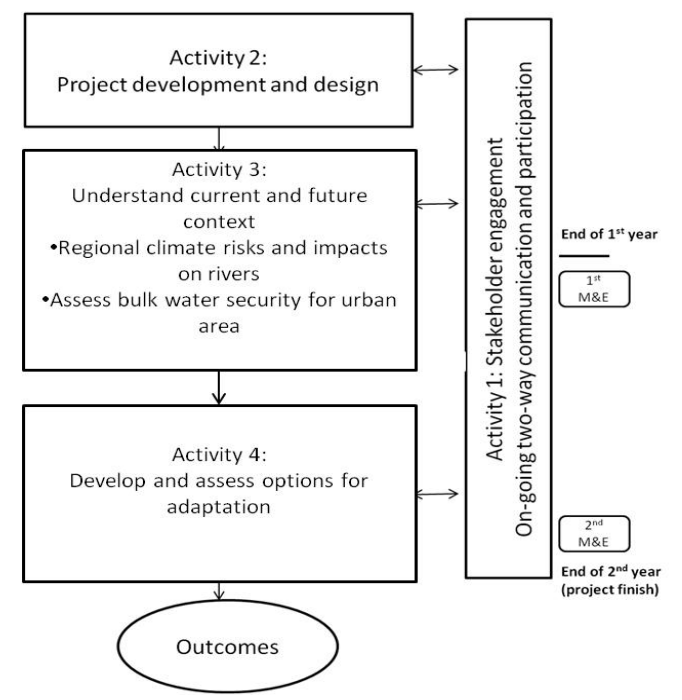

Figure 1. Framework for water security assessment and capacity building (Adapted from Kirono et al 2013)

Keywords: $\quad$ Sustainable urban development, climate change adaptation, hydrological modelling 


\section{INTRODUCTION}

Sustainable water resource management is a global issue of increasing complexity (Bogardi et al 2012). Rapid urbanisation and population growth increase the stress on the environment, given the need for resources and the impact of pollution; costs of infrastructure and maintenance increase as cities grow; and institutional arrangements increase in complexity given the needs of multiple actors and their expectations (Varis and Sonlyódy 1997, Agudelo-Vera et al 2011). These challenges are compounded in developing countries which face financial, natural resource and capacity limitations, and are accustomed to rely on traditional engineering solutions for major challenges (Vairavamoorthy and Sempewo 2011). In many developing countries economic and urban development is happening at an accelerated pace over a period of a few decades. As a result, urban lifestyle, economic activities and the associated environmental impacts are at pace with modern development, but infrastructure and social capacity development lag and are hindered by financial, institutional and social constraints (Ujang and Buckley 2002, Van der Bruggen et al 2010).

Urban development needs to be sustainable and resilient, i.e. able to adapt to changing anthropogenic and natural challenges. Climate change adds to the uncertainty that policy makers and water planners face in developing future water management strategies and policies (Brown et al 2012).

Adger et al. (2005) defined adaptation to climate change as "an adjustment in ecological, social or economic systems in response to observed or expected changes in climate to alleviate adverse impacts of change or take advantage of new opportunities. Adaptation requires an increase in the ability of individuals, groups or organisations to adapt to changes, and implement adaptation decisions, i.e. transforming that capacity into action in preparation for or in response to impacts generated by a changing climate." Adaptation also requires flexibility for change as impacts are often uncertain, and cooperation among multiple stakeholders; as solutions are not always well known and knowledge is often dispersed among various stakeholder groups. Thus, adaptation is closely linked to trust building, conflict resolution and balancing the interests of diverse stakeholders (Huntjens et al., 2012).

In international development, a key challenge of schemes implemented with donor funds has been a reliance on "imported" technologies and tools without due consideration for local context, and often implemented in isolation from local planners, researchers and engineers/specialists. This can easily lead to postimplementation failure due to cost and/or capacity for maintenance exceeding local resources (Ujang and Henze 2006). Overall, solutions need to be appropriate to the social, economic and technological in-country context, and thus tailored to the needs, resources and constraints of a country. Furthermore, for longevity, a sense of ownership is also required. Thus, in embarking in sustainable solutions for developing countries, capacity building is a key to the overall process (Brown et al. 2009).

This paper describes the application of an integrated research framework aimed at increasing the capacity of decision-makers and researchers in Indonesia to assess water security and develop adaptation strategies, in view of climate change, urbanization, population growth and infrastructure plans. Among the challenges of the project were information gaps, unreliable datasets, resource and capacity limitations. The framework adopts concepts such as integrated water management and total water cycle management for water resource management (Mitchell, 2006). Participation of local stakeholders at all stages of the process was essential to circumvent data limitations and prevent the pitfalls in developing adaptation capacity.

\section{CASE STUDY AREA}

Makassar city in the Mamminasata region, South Sulawesi province, Indonesia has a population of 1.3 million people and is projected to grow by twenty percent by 2020, increasing demand on water supplies (Nihon Suido, Nippon Koei Co. Ltd and KRI international 2011). Makassar city relies on surface water and groundwater for water supply: residential customers use mains water and shallow wells, while industrial and commercial customers rely on bore and mains water. Groundwater use is unregulated and anecdotal evidence suggests the drying of shallow wells in the dry season and sea water intrusion in coastal areas (Tjandraatmadja et al 2012a). Mains water is sourced from two major rivers, the Jeneberang River, and, the Maros River through the Lekopancing canal. These rivers feed five water treatment plants that supply the city. The Maros and the Jeneberang rivers are also the main surface water supply for the neighbouring regencies of Maros and Gowa (Tjandraatmadja et al 2012a). In the dry season, flow in the Maros river decreases by $25 \%$, reducing the supply to one of the two largest water treatment plants to the city. As a result additional extraction and transfer from the Jeneberang River is required. The Jeneberang River provides a reliable source of water supply thanks to the regulated flows from the Bili-Bili dam. The climate is tropical (24 to $32^{\circ} \mathrm{C}$ monthly averages), with a monsoonal wet season (November to May) and a dry season (April to October). 
The institutional set-up in the Mamminasata region is complex with multiple agencies at provincial, regency and municipal level sharing the jurisdiction over water resources, water delivery and sanitation. Informal networks are also highly complex, and consequently any effective change strategies require participation and cooperation of multiple stakeholders (Larson et al 2013).

Increasing the population's access to clean water is a key priority for Makassar. This will be achieved through upgrade of the production capacity $(+92 \%)$ of the treatment plants and rezoning of the distribution system coverage in the next 30 years. The plans assume that mains water consumption will increase from the current average of $117 \mathrm{~L} /$ person/d to the national level $(190 \mathrm{~L} / \mathrm{person} / \mathrm{d})$ by 2030 . Infrastructure upgrade projections are expected to reduce leakage from $30 \%$ to $15 \%$ and expand the network coverage from $63 \%$ to $85 \%$ of the population by 2025 . All infrastructure development will be subject to external funding. Despite of the strong seasonal dependency of the local water resources, government agencies were unable to assess the impact of future climate on the planning of future infrastructure services due to lack of local information on climate change and future projections.

\section{METHODOLOGY DEVELOPMENT AND IMPLEMENTATION}

Figure 1 and Figure 2 show, respectively, the framework and the actual implementation process, adopted to incorporate future climate into the vulnerability assessment for the city (see Kirono et al 2013 for the detailed description). The framework combined local knowledge and scientific inputs to integrate climate change to the overall infrastructure planning process. Activity 1: Stakeholder engagement: an on-going two-way process through the whole project to exchange knowledge between the project team and stakeholders and to ensure the robustness of the project methodology and the relevance of project outputs to stakeholders. The activity had two main purposes: (a) To gather local wisdom and address gaps in scientific knowledge with practitioner knowledge; and (b) To build-up a common knowledge base for the project team and stakeholders. This was achieved by designing strategies for Stakeholder Engagement, Monitoring and Evaluation and by adopting participatory and knowledge sharing activities (e.g. seminars, workshops, field tours, symposiums, and study visits) to introduce new concepts, challenge pre-conceptions and to share and disseminate research outcomes. The detailed engagement process is described in Larson et al (2012). Stakeholders, individuals or groups that were affected by or could affect the outcome of the project, were identified, mapped and consulted through interviews and workshops. Three stakeholders groups were identified based on their role, level of interest and engagement: (a) research team of professionals from multiple disciplines from CSIRO and UNHAS; (b) Partner organisations that could use the project outputs and contribute to the project implementation; and (c) Other organisations that could affect or be affected by the project in some way (over 40 private and government organisations and academics). By the end of the project over 500 people from government, non-government and the academic sectors had provided input and feedback, 233 people participated in knowledge sharing and training workshops and 295 people took part in information dissemination activities (one symposium, six mini symposia and a seminar). Other dissemination tools adopted included project newsletters in Indonesian, a stakeholder mailing list and a project website (www.rdfalliance.com.au/site/makassar.php) to provide access to the project reports and outputs.

Activity 2: Project development and design: the project scope and research objectives were defined in consultation with local stakeholders who used their contextual knowledge to identify the key challenges, priorities and desired outputs from the local perspective. Local champions facilitated the introduction of the team to local stakeholders, and helped organize a workshop of high-level representatives from government (city, provincial and national agencies), NGOs, academia, industry and donor agencies in Makassar. The workshop identified knowledge gaps, the case study area and the project objectives. Water security was the key priority for stakeholders and became the research focus. The major knowledge gaps identified were the lack of understanding of climate change impacts on water security, specifically the need for projections of climate change and the impacts on water supply (medium-term 2030) and the identification of potential adaptation options that could increase water security. The Mamminasata region was chosen as the case study area for climate change projections and surface water assessment, whilst Makassar city was the focus for adaptation. Following this activity, a suitably skilled multi-disciplinary project team comprised of researchers in environmental science, forestry, chemical and civil engineering, geography, climatology, economics, social science, communications and urban planning was assembled.

Activity 3: Understand current and future context: existing literature (scientific literature, government reports) and stakeholders input were gathered (via interviews and workshops) to gauge: (a) Scientific data availability on water supply, wastewater, groundwater, solid waste and future infrastructure plans, and (b) 
Institutional context and capacity (Larson et al 2012, 2013). The process consolidated the data and identified data gaps (Barkey et al 2011, Alexander et al 2012). There was limited data on environmental monitoring for water quality and groundwater use. A number of data records were not continuous or had to be checked prior to use. Research activities and methodologies were developed to address the information gaps. Scientific models were used to develop future climate projections and to assess their implications to surface hydrology, urban water security, soil erosion and to integrate climate change into future planning (CSIRO et al, 2012). Climate change projections were developed using five different Global Circulation Models (GCMs) models and downscaled to a $14 \mathrm{~km}$ grid using the CSIRO Conformal Cubic Atmospheric Model (CCAM) (Kirono et al, 2013). Impacts of the projected changes were then modeled using: (a) SIMHYD, to evaluate the future hydrology/streamflows of the Jeneberang and Maros rivers; (b) Projections of CCAM rainfall and evapotranspiration and GIS data were combined to evaluate future soil erosion and sedimentation in the Mamminasata region (CSIRO et al, 2012); and (c) REALM (Resource Allocation Model) to examine bulk water allocation scenarios and water security for Makassar city (Perera and James 2003), using as inputs CCAM projections, streamflows from SIMHYD, future population projections and infrastructure plans for the Mamminasata region (CSIRO et al, 2012; Neumann et al,2013).

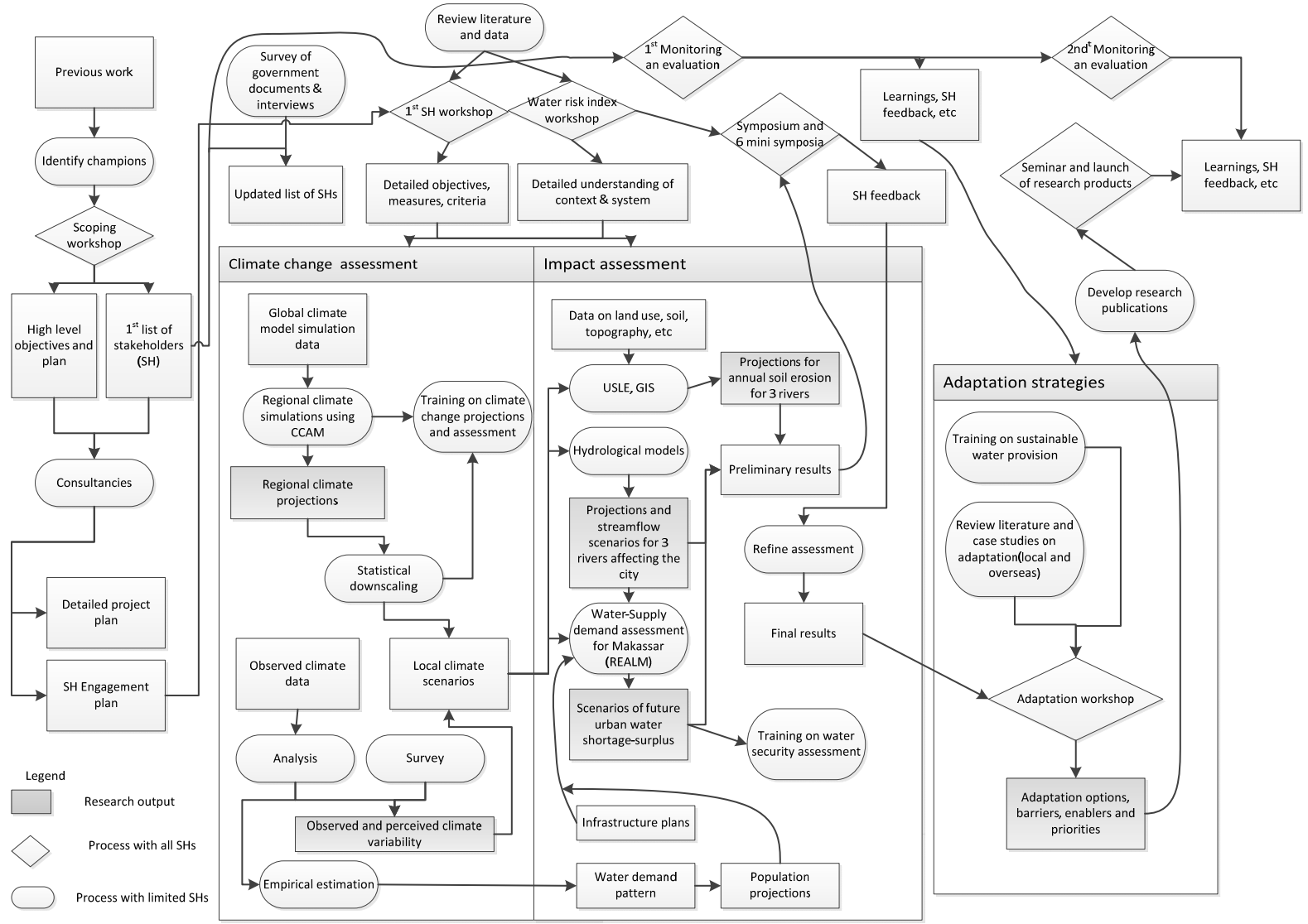

Figure 2. Framework implementation (adapted from Kirono et al 2013)

The modeling outputs are summarized in Table 1. The outputs from the various models were integrated to show how climate change data could be used and incorporated into risk assessment and decision-making. The evaluation of scenarios of water supply and demand based on future projections indicates that seasonality of water supply will persist in the areas supplied by the Lekopancing canal. Investment in infrastructure will increase supply capacity and meet over $90 \%$ of the urban water demand for four of the major treatment plants for Makassar, despite climate, for 2020 to 2039. The one plant that is dependent on the Lekopancing canal will continue to be subject to dry season shortages and supply over $40 \%$ of the demand for that period (Neumann et al 2013). However, further infrastructure upgrade will be required from 2040 onwards to meet growing water demand for the city. Water security whilst impacted by climate change would be more severely impacted by population growth, the associated water demand and the infrastructure capacity. For instance, an increase in water usage per capita to $160 \mathrm{~L} /$ person/day instead of $190 \mathrm{~L} / \mathrm{person} /$ day, could delay the need for infrastructure augmentation by 10years allowing more time for financing. 
Tjandraatmadja et al., Assessing urban water security and climate change adaptation in Makassar, Indonesia

Table 1. Future challenges for Makassar (2025s)

\begin{tabular}{|c|c|c|}
\hline Parameter & \multicolumn{2}{|l|}{ Context } \\
\hline Water demand & \multicolumn{2}{|c|}{ Increases with population and distribution area $(+120 \%)$. } \\
\hline Climate & $\begin{array}{l}\text { Annual temperature: } \uparrow\left(+0.3-0.4^{\circ} \mathrm{C}\right) \\
\text { Dry season rainfall reduction: } \downarrow 36 \% \\
\text { Wet season: no change in rainfall, shorter } \\
\text { duration (about } 12 \text { days) }\end{array}$ & $\begin{array}{l}\text { Rainfall variability interannual variability: } \uparrow \\
\text { Extreme rainfall intensity: } \downarrow \\
\text { Potential evaporation: } \uparrow(+12 \%)\end{array}$ \\
\hline Streamflow & $\begin{array}{l}\text { Mean daily streamflow } \\
\text { To Bili-Bili dam: } \downarrow(4-7 \%)\end{array}$ & $\begin{array}{l}\text { At Puca, near Lekopancing canal: } \downarrow(17-19 \%) \\
\text { Mean annual flow: } \downarrow \text { decrease }(7-27 \%) \\
\text { Mean dry season flow: } \downarrow(7-32 \%) \\
\text { Mean wet season flow: } \downarrow(7-28 \%) \\
\text { Number of days with low flow }\left(<2 \mathrm{~m}^{3} / \mathrm{s}\right) \text { : } \uparrow \text { by } 10 \text { to } 29 \%\end{array}$ \\
\hline Groundwater & $\begin{array}{l}\text { Recharge: } \downarrow \text {, Extraction: } \uparrow, \text { Water demand: } \uparrow \\
\text { Water quality at Jeneberang: } \downarrow \text {, Pollution: } \uparrow\end{array}$ & \\
\hline
\end{tabular}

Activity 4: Develop adaptation strategies: Provided with knowledge from Activity 3, training on adaptation and reviews of adaptation case studies were conducted (Tjandraatmadja et al 2012 b). In a workshop, examples of adaptation strategies from around the world and from Makassar were shared and participants used a modified Delphi process for assessing and ranking options. The process used individual decision-making, small groups and plenary activities to foster dialogue. Table 2 shows the adaptation options developed to improve the overall sustainability of water services at a range of levels by stakeholders. The top options selected and agreed in plenary were assessed for enabling mechanisms for implementation and identification of science gaps that require further investigation (Tjandraatmadja et al, 2012c).

\section{DISCUSSION AND CONCLUSIONS}

\subsection{Role of stakeholders}

In many developing economies, data can be difficult to locate and its availability and integrity is often limited, requiring a certain degree of flexibility and ingenuity to circumvent the lack of traditional datasets. Continuous engagement with local stakeholders facilitated the gathering of scientific information, furthered stakeholders' networks, created opportunities for social learning and knowledge dissemination which were relevant to local stakeholders' needs and practices. Stakeholder participation throughout the project also had two additional benefits: it brought together stakeholder groups which would typically not interact in day-today business allowing the formation of informal networks and facilitated the buy-in and ownership of new ideas and project outputs. The stakeholders were particularly important in determining the feasibility of adaptation options, given that implementation is highly dependent on social and institutional norms which are often undisclosed. The stakeholder engagement plan was a powerful tool to monitor the participation of stakeholders, monitor project progress, to ensure the relevance of the research; and it deliberately ensured that as many stakeholders as possible were reached. It also helped to address the challenge of teams operating from geographical disparate locations (Indonesia and Australia) and the multidisciplinary nature of the project. 


\subsection{Capacity building and sustainability}

The project delivered outputs that can assist stakeholders in sustainable planning and development: (a) Datasets (e.g. synthesis of local data about the water service context in the region, new data on future regional and local climate, on hydrology of key rivers in the area, erosion data, adaptation options); (b) Methodologies (e.g. integrated assessment of water security, participatory tools, options development); (c) New concepts (e.g. frameworks for risk assessment, integrated water management and stakeholder engagement), and (d) Areas for further research. The selection of an integrated model for water supplydemand that combined outputs from the other models (climate, hydrology), empirical data and projections (population, infrastructure) showcased the value of multidisciplinary collaboration for handling complex problems and hoped to reduce the silo mentality. The methodology can be used for replication of the analysis in other parts of the region and around the world. In addition, the datasets can be used in other assessments, e.g. climate impacts on agriculture, flooding, staged investment in infrastructure, etc.

The assimilation and the furthering of the knowledge generated after the life of a project is a major challenge, which requires capacity development to correctly interpret data and understand its significance and limitations (e.g. climate data, future projections, deterministic versus probabilistic estimates) - hence the use of training workshops and the focus on reaching a wide stakeholder audience - e.g. academics for their potential to propagate learning, and end users agencies to consider potential applications for outputs.

The project also considered anthropogenic and climate pressures in a holistic context, relevant to decisionmaking. Often climate change is perceived as a distant factor unrelated to the more urgent priorities. Prior to the is research, climate change was associated with shortage of water by majority $(68 \%)$ of stakeholders (Larson et al 2012) and many of the stakeholders came to the realization that climate change could have a more direct impact on their activities as it could be quantified through streamflows and associated interventions regarding water security.

\subsection{Developing adaptation capacity}

Adaptation options developed by stakeholders covered a wide range of elements in the water cycle and demonstrated openness to some of the new concepts introduced (e.g. total water cycle management, mindset change, decentralised solutions). The options suggested were at various stages of maturity regarding the potential for implementation. Some were undergoing actual technical feasibility analysis, e.g. water reuse at the treatment plant which could increase water production by 7\%; whilst other measures required more extensive exploration, e.g. greywater reuse. Overall, the options will require further analysis and feasibility assessment to determine their impact on water sustainability for the city. It is unlikely that a single measure alone will solve the water security issue; instead a mix of options will most likely be required. Yet, through the process stakeholders have initiated the process of identification of gaps in knowledge, barriers and enablers to implementation. Furthermore they agreed that adaptation will require the adoption of both technological and mindset change to be truly effective.

Feedback obtained at the conclusion of the project through the monitoring and evaluation process has indicated a high level of satisfaction by stakeholders with the research outcomes. In addition, a number of agencies have signaled the intent for adoption of research outputs into their next infrastructure planning round (Larson et al 2012).

\subsection{Conclusions and Recommendations}

The inclusion of climate change adaptation into water resource management planning and decision-making is challenging task, particularly in cities such as Makassar, Indonesia, which face complex social, technical, environmental and social challenges, and suffer from severe data, capacity and financial limitations. The framework for water security assessment here presented integrated top-down and bottom up knowledge (scientific modelling outputs and local knowledge) to identify vulnerability and assess the effectiveness of planned infrastructure to climate change and urban development and to identify a range of adaptation options which can assist in increasing the future security of water supply. More importantly, the process not only generated new climate data previously unavailable, but created an environment conducive of learning, developed trust between the project team and stakeholders, increased local environmental awareness and adaptation capacity. 
Tjandraatmadja et al., Assessing urban water security and climate change adaptation in Makassar, Indonesia

\section{ACKNOWLEDGMENTS}

The research was funded by the CSIRO-AusAID Research for Development Alliance (www.rfdalliance.com.au). We thank the contribution from all stakeholders involved in the project.

\section{REFERENCES}

Adger, W.N., Arnell, N.W, Tompkins, E.L. (2005) Successful adaptation to climate change across scales, Global Environment Change, 15(2), 77-86.

Agudelo-Vera C.M., Mels A.R., Keesman K.J. and Rijnaarts H.H.M. (2011) Resource management as a key factor for sustainable urban planning, Journal of Environmental Management, 92, 2295-2303.

Barkey R.A., Achmad A., Kaimuddin, et al. (2011) Review on water service provision in Makassar city, Indonesia. Hasanuddin University, Makassar, Indonesia. A report submitted to CSIRO, Australia.

Bogardi J.J., Dudgeon D., Lawford R., Finkwerbush E., Meyn A., Pahl-Wostl C., Vielhauer K. and Vörösmarty C. (2012) Water security for a planet under pressure: interconnected challenges of a changing world call for sustainable solutions, Current Opinion in Environmental Sustainability, 4, 35-43.

Brown A., Dayal A., Del Rio CR. (2012) From practice to theory: emerging lessons from Asia for building urban climate change resilience, Environment and Urbanization, 24(2), 531-556. DOI:10.1177/0956247812456490.

CSIRO (2012) The impacts of climate change and urban development on future water security and the adaptation options for Makassar City, Indonesia. A synthesis of findings from Climate Adaptation through Sustainable Urban Development Research Project (SUD). http://www.rfdalliance.com.au/site/makassar.php

Huntjens, P., Lebel, L., Pahl-Wostl, C., Camkin, J., Schulze, R., Kranz, N. (2012) Institutional design propositions for the governance adaptation to climate change in the water sector, Global Environmental Change, 22,67-81.

Kirono D.G.C, Larson S., Tjandraatmadja G., Leitch A, Neumann L., Maheepala S., Barkey R.A., Achmad A., Selintung M. (2013) Adapting to climate change through urban water management: a participatory case study in Indonesia, Regional Environmental Change, doi: 10.1007/s10113-013-0498-3

Larson S., Kirono D.G.C., Barkey R.A., Tjandraatmadja G. (2012) Stakeholder engagement within the Climate Adaptation Through Sustainable Urban Development in Makassar-Indonesia Project, the First year report. A Report, CSIRO, Australia.

Larson S., Alexander K.S., Djalante R. and Kirono D.G.C. (2013), The added value of understanding informal social networks in an adaptive capacity assessment: Explorations of an urban water management system in Indonesia; Water Resources Management, 27, 4425-4441.

Mitchell V.G. (2004) Integrated Urban Water Management: A review of current Australian practice, Australian Water Conservation and Reuse Program -CSIRO and Australian Water Association, Report No. CMIT-2004-075.

Neumann L., Tjandraatmadja G., Kirono D.G.C., Selintung M. (2013) Integrated assessment of water security: Makassar, Indonesia, MODSIM 2013, Adelaide, December 1-6.

Nihon Suido Consultants Co. Ltd., Nippon Koei Co. Ltd and KRI International Corp. (2011) The preparatory survey on the Makassar water supply development project (Stage II) in the Republic of Indonesia. Interim Report, Volume I, Main Report. Japan International Cooperation Agency, Ministry of Public Works, South Sulawesi Province, PDAM Makassar, PDAM Gowa, PDAM Maros and PDAM Takalar, The Republic of Indonesia.

Perera B.J.C and James B. (2003) A generalised water supply simulation computer software package - REALM, Hydrology Journal 26, 67-83.

Tjandraatmadja G., Larson S., Kirono D., et al. (2012a) Challenges in urban water provision for Makassar, South Sulawesi, Indonesia. A report, CSIRO, Australia.

Tjandraatmadja G., Stone-Jovicich S., Muryanto I., et al. (2012b) Tools for urban water management and adaptation to climate change. A Report, CSIRO, Australia.

Tjandraatmadja G., Larson S., Kirono DG.C., Salman D., Barkey R.A. and Selintung M. (2012c) Climate Adaptation through Sustainable Urban Development: Developing Adaptation Options to Improve Future Water Security in Makassar City. CSIRO AusAID Alliance and Climate Adaptation Flagship, Melbourne, Australia.

Ujang Z.and Buckley C. (2002) Water and wastewater in developing countries: present reality and strategy for the future. Water Science and Technology, 46:1-9.

Vairavamoorthy K and Sempewo J (2011) Distribution of Water: developing countries, in Encyclopedia of Environmental Health, , pp.137-146, Elsevier B.V.

Van der Bruggen B., Borghgraef K., Vinckier C. (2010) Causes of water supply problems in urbanized regions in developing countries, Water Resource Management, 24, 1885-1902, DOI: 10.1007/s11269-009-9529-8.

Varis O., Sonlyódy L. (1997) Globalization and urban water: can sustainability be afforded?, Water Science and Technology, 21-32. 